\title{
Research on Nutritional Interventions to Recuperation for the Elite Swimmer in the Period Preparation for Competition of 29th SEA Games at Malaysia in 2017
}

\author{
Linh Nguyen Thi My, Thinh Do Trong, and Phuong Le Quy
}

\section{ABSTRACT}

The purpose of the study was efficiency the interventions nutritional to recovery and the requirements related to the use of food and food ingredients for health stability, promotion efficiency of the competition exercises of swimmer by through the indicators reflect about recovery: Hematocrits, Hemoglobin, Testosterone, Creatinine, Rest lactic acid, Maximal Lactic Acid, Creatinine, Blood Pressure, Weight. The results of the study show that, after 6 weeks of the experimental, the swimmer's health is well maintained, swimmer's fitness strength and ability to adapt to the physical training and the swimmer have won 8 gold medals at the competition at the SEA Games 2017 in Malaysia.

Keywords: nutrition, food supplements, physical, health.

\author{
Submitted : April 13, 2021 \\ Published : May 04, 2021 \\ ISSN: $2593-8339$ \\ DOI: $10.24018 /$ ejmed.2021.3.3.813 \\ Linh Nguyen Thi My \\ Thinh Do Trong \\ Phuong Le Quy* \\ *Corresponding Author
}

\section{INTRODUCTION}

According to many sports scientists and in practice of sports also show that, problem about nutrition and recovery for athletes are needed and very important in the time phase excercise preparebefore the competition. To study the effects of nutrition and recovery of Vietnamese swimmers in 6 weeks during prepare to the SEA Games 29th competition in Malaysia in 2017, we do examine the rehabilitation of optimal function by through some indicators of biomedical with the female swimmer Nguyen Thi Anh Vien, who have won eight gold medals on SEA Games 28th in Singapore in 2015.

\section{A. Basis of Calculation and Determination of Daily Energy Demand for Athletes}

In the field of sport, the use of dietary supplements has been studied extensively in the world and the use of these nutritional supplements has become increasingly important in protect the health, add energy, replenish the micronutrient deficiency, improve workout effectiveness, prevent injury, improve the ability to recover quickly and improve performance for athletes. However, in order to verify the energy requirements needed and sufficient for the athlete to meet the training requirements in the preparation training phase, it is necessary to calculate the amount of energy necessary for the body such as energy use for basic metabolism (maintenance of vital functions of the body), energy used for normal daily activities (learning, recreation, communication ...) and energy used for activities daily exercise sports. In addition, the daily energy requirements depend on the morphology (height, weight) and age. In order to calculate and determine the energy used for normal daily activities and the energy used for sports exercise, there are

many calculations. According to the American Dietetic Association, the American College of Sports Medicine and the American Dietetic Association [5], the energy used in daily diet and exercise training of athletes includes:

- Resting metabolic rate/day (RMR/day):

$$
\begin{aligned}
\mathrm{RMR} / \mathrm{day}= & 655,1+(9.6 \times \text { body weigh } \mathrm{kg})+(1.8 \times \\
& \text { height } \mathrm{cm})-(4.7 \times \text { age })
\end{aligned}
$$

\section{- The daily energy requirement (ER/day):}

According to the British Sports Federation (Ronald J. Maughan) in 2012 [4], the daily energy requirement for $1 \mathrm{~kg}$ of body weight is $1,334 \mathrm{kcal}$ per hour and the energy for daily activities is the following formula [4]:

$$
\mathrm{ER} / \mathrm{day}=1.334 \mathrm{kcal} \times \text { body weigh } \mathrm{kg} \times 10 \text { hours }
$$

\section{- Energy for daily exercise (EE/day):}

The calculation of the daily exercise energy requirement for athletes depends on the type of activity the athlete performs. According to the Nutrition Association (2014), athletes who practice endurance sports will spend between 600 and $1200 \mathrm{kcal}$ per hour of exercise and athletes practicing in specialized sports. The strength and capacity will cost you from 312 to $672 \mathrm{kcal} / \mathrm{hr}$ of exercise and fitness, from the American College of Sports Medicine and the Canadian Dietitian for daily exercise [5]. The athlete is calculated according to the following formula:

$\mathrm{EE} /$ day $=$ Calories consumed $/$ hour of exercise $\times$ Number of hours excercise/day 


\section{- Total energy consumption/day (TEC/day):}

Total energy consumption/day is the sum of the kcals energy of the base energy plus the normal daily energy plus the energy for the daily exercise of the athlete and calculated as follows:

$$
\mathrm{TEC} / \text { day }=\mathrm{RMR}+\mathrm{DER}+\mathrm{EDE} / \mathrm{day}
$$

\section{B. Determining the Daily Energy Needs of Athletes Nguyen Thi Anh Vien during the Preparation Training Phase for Competition}

Through a survey on dietary status and according to research results of 2016, nutritionists Nguyen Thanh Lam, Dang Ha Viet and colleagues said that through 3 main meals daily at the Center for National Fetter Sports in general and the Center for National Fetal Sports in Ho Chi Minh City. Ho Chi Minh City has provided energy for athletes of national youth sports teams and national sports teams to prepare for national competitions and annual international tournaments average in the range $4500 \mathrm{kcal} / \mathrm{day}$.

Based on the formulas for calculating the daily energy demand for athletes that the sports scientists of the world have set out as outlined in section A, the topic of application and calculation determines the demand The energy needed to meet the training needs of the athlete preparing for the competition for athlete Nguyen Thi Anh Vien suitable with the sport characteristics and close to the form (height, weight), age and sex of the athletes as follows:

- The daily energy needs of swimmer Nguyen Thi Anh Vien:

Resting metabolic rate/day $(\mathrm{RMR} /$ day $): 655,1+(9.6 \times 62$ $\mathrm{kg})+(1.8 \times 172 \mathrm{~cm})-(4.7 \times 21 \mathrm{t})=1471,2 \mathrm{kcal} / \mathrm{day}$.

The daily energy requirement (ER/day): $1.334 \mathrm{kcal} / \mathrm{kg} \times$ $62 \mathrm{~kg} \times 10$ hours $=840.42 \mathrm{kcal} / \mathrm{day}$.

Energy for daily exercise (EE/day): $600-1200 \mathrm{kcal} / \mathrm{hour}$ $\times 6$ hours $/$ day $=3600 \rightarrow 7200 \mathrm{kcal} /$ day.

An average of $5400 \mathrm{kcal} /$ day $\rightarrow 2700 \mathrm{kcal} /$ session.

Total Energy Demand (TNL) per day: 1471,2+ 840.42+ $3600 \rightarrow 7200 \mathrm{kcal}=5.911,62 \rightarrow 9.511,62 \mathrm{kcal} /$ day .

Thus, the total daily energy demand of swimmer Nguyen Thi Anh Vien on average will be 7,711.62 kcal per day.

- Determining the energy need to intervene through dietary supplements before, during and after daily exercise for female athlete Nguyen Thi Anh Vien:

Based on the study of the energy supply to the athlete's body through nutrition at the NTPF centers as described in Section A and calculating daily energy needs as presented In Section B, energy needs to be supplemented during daily exercise of athletes swimming Nguyen Thi Anh Vien during the preparation phase of the competition and is calculated according to the following formula [7], [5], [4]:

Energy (kcal) for exercise of 3 main meals: Total kcal of 3 main meals - (kcal basis + daily kcal)
Energy (kcal) for exercise through 3 main meals:

$4500 \mathrm{kcal} /$ day $-(1448,35 \mathrm{kcal} /$ day $+804.42 \mathrm{kcal} /$ day $)$ $=2252.77 \mathrm{kcal} / \mathrm{day}$.

The energy requirement (kcal) needed for additional intervention to meet daily exercise requirements: 5400 $\mathrm{kcal} /$ day $-2252.77 \mathrm{kcal} /$ day $=3147.23 \mathrm{kcal} /$ day .

Energy needs (kcal) need additional intervention to meet the requirements for each session of training: 3147.23 $\mathrm{kcal} / \mathrm{ngày}: 2$ buổi tập $=1573.615 \mathrm{kcal} / \mathrm{session}$.

\section{MATERIALS AND METHODS}

Research method: In study process, we used the experimental method of pedagogy, biomedical method and statistics mathematical to evaluate the effectiveness of nutritional intervention and rehabilitation to the swimmer Nguyen Thi Anh Vien at the preparation stage (6 weeks) befor she go to the participate competition of the 29th SEA Games in Malaysia in 2017.

Objects for research: The female swimmer Nguyen Thi Anh Vien was born in 1996, 172 cm height and $63 \mathrm{~kg}$ weight, who have won eight gold medals at the Singapore SEA Games in 2015.

Research time: in 6 weeks of the training preparation period for competition before competition SEA Games 29 in Malaysia.

\section{RESULT}

A. Building of Nutrition Intervention Program and Rehabilitation through Functional Foods and Drinking Water of Athlete Swimming Nguyen Thi Anh Vien in the Preparation Phase of Competition

Based on theoretical and practical training for athletes in the period preparation of the competition, based on the formula for actual energy needs to be added to the athlete as described in Section A, by studying the function and effect of the type of real Functional fit and comfort with the athlete before, during and after training, while meeting the need for specific activities of the sport. The topic is to build and implement a nutritional supplement program (kcal) using functional foods that are appropriate to the characteristics of sports in order to improve the effectiveness of exercise. and enhance the recovery capacity for athletes Nguyen Thi Anh Vien during the preparation phase as follows:

TABLE I: FUNCTIONAL FOODS THAT PROVIDE ENERGY DURING EXERCISE

\begin{tabular}{|c|c|c|c|c|c|c|c|}
\hline \multirow[b]{2}{*}{ No. } & \multirow{2}{*}{ Provide energy } & \multirow{2}{*}{$\begin{array}{l}\text { Unit of } \\
\text { measure }\end{array}$} & \multirow[b]{2}{*}{ Kcal } & \multicolumn{3}{|c|}{ Session } & \multirow[b]{2}{*}{ Total kcal } \\
\hline & & & & Before & $\begin{array}{c}\text { in } \\
\text { during }\end{array}$ & $\begin{array}{l}\text { after } \\
\text { finish }\end{array}$ & \\
\hline 1 & Energy GEL & $32 \mathrm{~g}$ & 100 & 1 & 0 & 1 & 200 \\
\hline 2 & Vitagor & $75 \mathrm{~g}$ & 280 & 1 & 1 & 1 & 840 \\
\hline 3 & Drink Sport & $330 \mathrm{~g}$ & 140 & 0 & 0 & 2 & 280 \\
\hline 4 & Energy bar & $45 \mathrm{~g}$ & 200calo & 1 & 0 & 1 & 0.4 \\
\hline 5 & Whey & $30.4 \mathrm{~g}$ & 120 & 1 & 0 & 1 & 240 \\
\hline \multicolumn{7}{|c|}{ Total supply kcals / session } & $1560.4 \mathrm{kcal}$ \\
\hline
\end{tabular}

Energy needs need additional intervention for training: Real calorie needs - Kcal is for training of 3 main meals.

According to the formula above, energy needs (kcal) need additional intervention in the daily training for swimmer Nguyen Thi Anh Vien in the preparation phase as follows: 
TABLE II: FunCTIONAL FoOdS PROVIDE VITAMINS, MineRALS

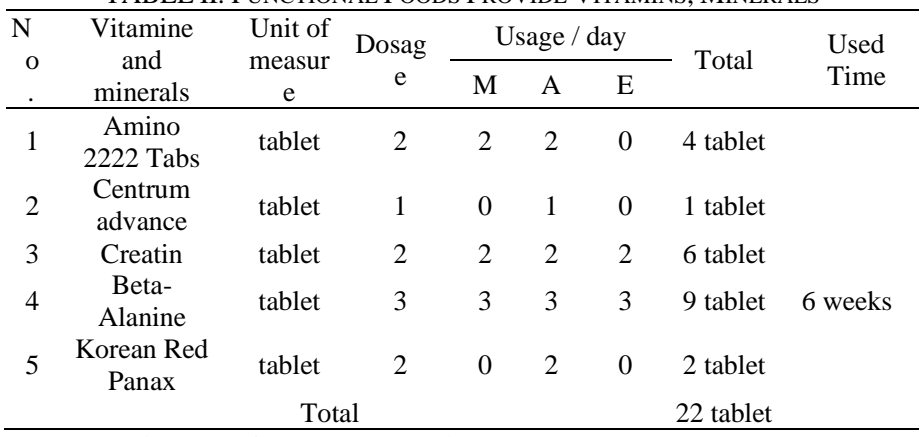

M: Morning; A: Afternoon; E: Evening.

B. Efficacy of Nutrition Intervention and Recovery in the Preparation Stage with the Female Athlete Nguyen Thi Anh Vien

1. The recovery through biomedical indicators:

After 6 weeks of nutritional use at the preparation stage for the competition and to assess the effectiveness of nutritional intervention and recovery at this stage with female swimmer Nguyen Thi Anh Vien, we have advanced Examination of 9 indicators reflects the recovery of athletes at the beginning of the preparation phase and at the end of the preparation phase for competition.

TABLE III: RESULTS TEST OF 9 BIOMEDICAL INDICATORS OF THE SWIMMER NGUYEN THI ANH VIEN AFTER 6 WEEKS OF TRAINING IN THE PREPARATION STAGE FOR COMPETITION

\begin{tabular}{|c|c|c|c|c|}
\hline No. & Parameter & $\begin{array}{c}\text { Fist time } \\
(17.6 .2017) \\
\end{array}$ & $\begin{array}{c}\text { Second time } \\
(17.8 .2017)\end{array}$ & Reference $\left({ }^{*}\right)$ \\
\hline 1 & Hematocrits (\%) & $49.0 \pm 3$ & $49.1 \pm 3$ & 40 to 50 \\
\hline 2 & Hemoglobin $(\mathrm{g} / \mathrm{dl})$ & $15.9 \pm 1.2$ & $14.1 \pm 0.8$ & $\begin{array}{l}13.5 \text { to } 18(\mathrm{H})- \\
11.5 \text { to } 16(\mathrm{~W})\end{array}$ \\
\hline 3 & Testosteron (ng/dl) & $36 \pm 1.2$ & $36.2 \pm 1.3$ & 8.0 to 60.0 \\
\hline 4 & $\begin{array}{l}\text { Rest Axit lactic } \\
(\mathrm{mmol} / \mathrm{l})\end{array}$ & $2.0 \pm 10.0$ & $1.5 \pm 5.7$ & $0.5-2.2 \mathrm{mmol} / \mathrm{l}$ \\
\hline 5 & $\begin{array}{l}\text { Max Axit Lactic } \\
(\mathrm{mmol} / \mathrm{l})\end{array}$ & $14.0 \pm 8.5$ & $14.3 \pm 6.3$ & $12-18 \mathrm{mmol} / \mathrm{l}$ \\
\hline 6 & Rest HR (1/ph) & $52 \pm 2.0$ & $52 \pm 3$ & $50-601 / p h$ \\
\hline 7 & $\begin{array}{l}\text { Blood press } \\
(\mathrm{mmHg})\end{array}$ & $70 / 110$ & $70 / 110$ & $\begin{array}{c}\text { 80/120 mm } \\
\mathrm{Hg} .\end{array}$ \\
\hline 8 & Creatinine $(\mathrm{mg} / \mathrm{dl})$ & $0.93 \pm 0.20$ & $0.8 \pm 0.2$ & 0.5 to 1.5 \\
\hline 9 & Body weigh (kg) & 63.1 & 62.8 & N/A \\
\hline
\end{tabular}

\section{Results competition at the 29th SEA Games in Malaysia in 2017}

At the 29th Malaysia SEA Games in 2017, swimmer Nguyen Thi Anh Vien have achievement excelled in competition. She won 8 gold medals and 2 silver medals.

TABLE IV: COMPETITION RESULTS OF THE SWIMMER NGUYEN THI ANH Vien at the SEa Games IN 2015 and SEA Games IN 2017.

\begin{tabular}{|c|c|c|c|c|c|}
\hline \multicolumn{3}{|c|}{ SEA Games 28 in 2015} & \multicolumn{3}{|c|}{ SEA Games 29 in 2017} \\
\hline Events & Result & Medal & Events & Result & Medal \\
\hline $200 \mathrm{~m}$ FS & $1: 59.27 \mathrm{GR}$ & & $200 \mathrm{~m}$ FS & $1: 59.24 \mathrm{GR}$ & \\
\hline $400 \mathrm{~m}$ FS & 4:08.66 GR & & $400 \mathrm{~m}$ FS & 4:10.96 & \\
\hline $800 \mathrm{~m} \mathrm{FS}$ & $8: 34.85 \mathrm{GR}$ & & $800 \mathrm{~m}$ FS & $8: 35.55$ & \\
\hline $200 \mathrm{~m} \mathrm{BK}$ & $2: 14.12$ GR & & $200 \mathrm{~m} \mathrm{BK}$ & 2:13.64 GR & \\
\hline $200 \mathrm{~m} \mathrm{BR}$ & $2: 31.16$ & Gold & $200 \mathrm{~m} \mathrm{BR}$ & 2:30.89 NR & Gold \\
\hline $200 \mathrm{~m} \mathrm{BF}$ & $2: 11.12 \mathrm{GR}$ & & $100 \mathrm{~m} \mathrm{BK}$ & $\begin{array}{c}\text { 1:01.89 GR, } \\
\text { NR }\end{array}$ & \\
\hline $200 \mathrm{~m} \mathrm{IM}$ & $2: 13.53 \mathrm{GR}$ & & $200 \mathrm{~m} \mathrm{IM}$ & $2: 14.25$ & \\
\hline $400 \mathrm{~m} \mathrm{IM}$ & $4: 42.88 \mathrm{GR}$ & & $400 \mathrm{~m} \mathrm{IM}$ & $4: 45.82$ & \\
\hline $100 \mathrm{~m} \mathrm{FS}$ & $56.05 \mathrm{NR}$ & Silver & $100 \mathrm{~m}$ FS & $55.76 \mathrm{NR}$ & Silur \\
\hline $50 \mathrm{~m} \mathrm{BK}$ & 29.40 & Bronze & $50 \mathrm{~m} \mathrm{BK}$ & $29.26 \mathrm{NR}$ & Silver \\
\hline \multicolumn{3}{|c|}{8 Gold, 1 Silver and 1 Bronze } & \multicolumn{3}{|c|}{8 Gold, 2 Silver } \\
\hline \multicolumn{6}{|c|}{ GR: SEA Games Record NR: National Record. } \\
\hline
\end{tabular}

\section{DISCUSSION}

Modern sports show that that the science of coaching is do not to do athletes to exercise lighterly but still have high athletic performance. The essence of sports science is the application of scientific achievements into the training and training of athletes in a reasonable way to help athletes have the ability to absorb the volume of exercise increasingly higher intensity This is a great way to increase the capacity and capacity of your body's functions, to develop and improve your fitness, and to improve your fitness level. Meeting the requirements of sports competition is a drastic competition in terms of intensity and capacity of the body in terms of physical strength, capacity of function aiming to good achieve results sports and win.

In summary, the regimen for rehabilitation plays an important role in ensuring that athletes are physically fit, performing well on a rigorous training process that improves their ability to function, force. And is one of the indispensable factors in modern day training. Especially in the pre-match training stage, nutrition and recovery play a decisive role for the athlete to achieve optimal fitness and fitness to ensure high athletic performance.

Nutritional supplement is the use of foods, food ingredients, nutrients. It is intended to be used outside of the normal diet with the goal of achieving fitness or fitnessspecific performance gains or restoring fitness to athletes [7]. Today, dietary supplements are used very commonly in society, especially in countries with advanced science in the world. According to US nutritionists, about half of the US population now use some form of nutrition or nutrients to supplement their diets [4], [5], [7]. This ratio is similar in many other countries in the world and in Vietnam.

\section{LiMiTATIONS}

The limitation of this study is that the number of survey subjects is still quite small and does not incorporate gender matching. However, such limitations could be mitigated with further research in the near future.

\section{CONCLUSION}

The results test presented in Table III indicate that the biomedical indicators through 2 time tests are quite stable. The health of the athlete is always well recovered by the indicators almost no change. This reflects the athlete's body adapting to the loads of exercise in training and the dietary intervention and recovery at this stage has yielded clear benefits for swimmer Nguyen Thị Ánh Vien.

The result of the competition in Table IVshows that, in the 10 competition events, female swimmer Nguyen Thi Anh Vien have had five events with swimming achievements higher than SAE Games 28 in 2015 (increasing rate achievement is\%).

With the results of the SEA Games in 2015 compared to the SEA Games in 2017 said that, the problem of nutrition and recovery is indispensable and it is as important as physical training for athletes. It can be said that, in the preparation phase competitiom, the nutritional intervention 
and recovery for athletes is crucial to the performance in the competition of athletes.

\section{REFERENCES}

[1] David Klossner, Sports Medicine Handbook, National Collegiate Athletic Association Printed in the United States of America, 2013.

[2] Christophe Hausswirth, Inigo Mujika, Recovery for Performance in Sport, Human Kinetics Publishers, 2013.

[3] Maglischo Er. W. Swimming Fastest, Human Kinetics Publishers. 2003.

[4] Ronald J. Maughan, Nutrition in Sport. Blackwell Science - United Kingdom, 2000.

[5] Nanncy Clark, Sports Nutrition Guibook, Human Kinetics Publishers. 2014.

[6] Nutrition and Athletic Performance, Dietitians of Canada, the Academy of Nutrition and Dietetics and the American College of Sports Medicine, 2016.

[7] Heather Hedrick Fink, Lisa A. Burgoon, Alan E. Mikesky, Practical Applications in Sports Nutrition, Jones and Bartlett Publishers. 2016.

[8] Olympic success, Australian Sport Commission, 2002.

[9] Rebecca K. Tanner and Christopher J. Gore, Physiological Tests for Eliete Athletes, Human Kinetics Pblishers, 2013.

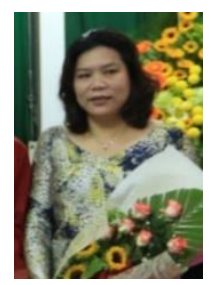

\section{Linh Nguyen Thi My}

Palce and date of birth: Ho Chi Min city, Viet Nam, 1978.

Doctor of Sport (Specialized in swimming).

Head of Training, Scientific Management and International Cooperation of University of Sports and Sports, HCMC (Viet Nam).

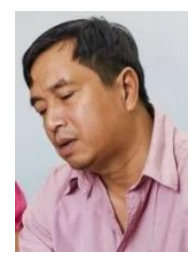

Thinh Do Trong

Palce and date of birth: Viet Nam, 1953.

Doctor of Sport.

Former Head of the Department of Water Sports, Vietnam Sports and Physical Education Commission.

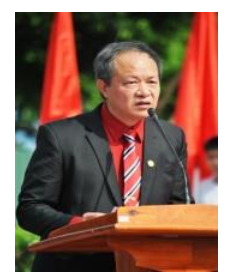

Phuong Le Quy

Palce and date of birth: Thái Bình Province, Viet Nam, 1957.

Professor, Doctor of Sports Medicine.

Chairman of the Science and Training Council of University of Sports and Sports, HCMC. 